\title{
V \\ The Library is Dead, Long Live the Library! The Practice of Academic Librarianship and the Digitall Revolution
}

\author{
by Lyman Ross and Pongracz Sennyey
}

Available online 12 February 2008

As a direct consequence of the digital revolution, academic libraries today face competition as information providers. Using Richard N. Foster's technology $S$ curves as the analytical model, this article shows that academic libraries are in the midst of discontinuous change by questioning a number of assumptions that support the current practice of academic librarianship. The authors challenge these assumptions, and analyze the manner in which digital communications affect academic libraries.

Lyman Ross is a Systems Librarian, University of Vermont Libraries, Bailey/Howe Library, University of Vermont, Burlington, VT 05405-0036, USA $<$ lyman.ross@uvm.edu>; Pongracz Sennyey is a Associate Director of Libraries, Furman University 3300 Poinsett Highway,

Greenville, SC 29673-3004, USA <pongracz.sennyey@furman.edus.

\section{INTRODUCTION}

It has become cliche to say that the digital revolution has changed the nature of information, but the fact remains that it has. The prevalent format, the speed of information creation, delivery and dissemination, and user needs and expectations have all changed. It has transformed scholarly communication as scholars adapt their teaching and research strategies to the new information environment. It is facilitating an increase in scholarly output in fields that were already expanding faster than libraries' ability to collect. Furthermore, it is enabling researchers to share vast quantities of raw research data. Researchers are turning away from traditional publishing venues and are opting to disseminate their findings and data in community vetted forums. As a consequence, libraries now face competition as information providers. The academic audience is no longer captive. Students and scholars can increasingly bypass the library to satisfy their information needs. These changes are disruptive, as they challenge the traditional role, purpose, and operations of the library, which together amounts to a paradigm shift.

Richard N. Foster postulates the thesis, known as technology $S$ curves, to explain how technological advances succeed 'each other' in the marketplace (Fig. 1) ${ }^{1}$. Foster presents a compelling model with which to interpret the changing information landscape. According to this theory, new technologies perform poorly in their early days when compared with the dominant technology. However, after a period of slow improvement, the performance of the emerging technology improves exponentially and quickly outperforms the old. Substantive yields in improvement are observed for a period until the performance of the new technology tapers off in turn, and diminishing returns set in. It is at the take-off point of the curve that new technologies tend to replace old ones in a discontinuous fashion. This is also the point when incumbents are most vulnerable, because they are penalized for switching too early, but risk falling behind when the new technology takes off in an exponential fashion ${ }^{2}$. Looking at librarianship in this paradigm, the profession has reached a point of diminishing returns as it continues to tinker with its traditional protocols and services, while emerging technologies are improving at an exponential rate. 
Figure 1

Technology S Curve

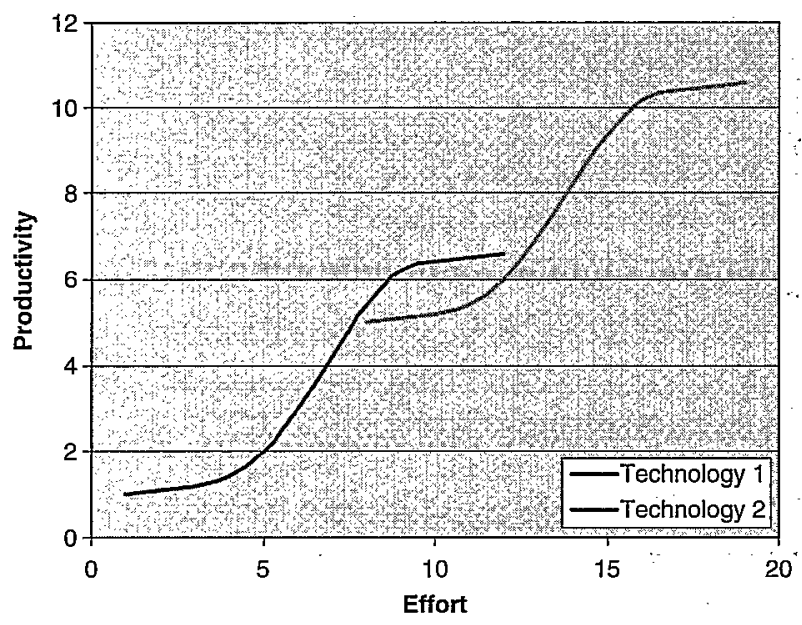

chains is the very symbol of what the popular imagination regards as a strange and ignorant time, whereas in reality, the chains are indicative of a scarce and expensive commodity, written information. As we all know, the invention of printing greatly reduced the cost of reproducing information but it also increased its volume and so libraries continued to grow and prosper as a way to share what remained a costly commodity. Faced with ever growing collections, librarians devised classification and cataloging systems that would make sense of the world's knowledge. This was the age of positivism when each advance in science and literature was seen as new and important. In this environment, libraries were regarded as laboratories of the mind, or the hearts, of universities and preserving information seemed a very important task. Thus academic libraries purchased and preserved materials, even if it had little current interest, for a later day, creating what is now known as a "long tail."

The Internet has made a significant shift in the environment in which libraries find themselves and is making our professional assumptions seem as foreign as a medieval manuscript in chains. The Internet has lowered the cost of propagating information to negligible levels ${ }^{7}$. This fact diminishes the value of local collections and services. Libraries are no longer islands of information, but one among many nodes through which information flows to the users. Thus the replicative effort invested by each libraiy in collecting, organizing, and providing information is becoming a thing of the past. A single player could provide these services regardless of the patrons' geographic location. There are no technical obstacles for jobbers to provide the journal content, manage the access, design the user interface, and federate searching to library journal collections. This is the same dilemma that many players in the information marketplace are struggling with already, as the examples of the effect of Netflix on Blockbuster's fortunes, or the Internet's effect on the news industry, illustrate. Libraries, however, still operate under the assumption that their physical location is critical, when in reality their placement on campus is progressively less important. The shift from print to electronic serials begun in the early $1990 \mathrm{~s}$ is a harbinger of things to come as soon as the scholarly monograph shifts formats as well.

\section{"The internet has made a significant shift in the environment in which libraries find themselves and is making our professional assumptions seem as foreign as a medieval manuscript in chains."}

But the competitive market environment is the most significant change libraries face today. This is altogether unprecedented in the history of librarianship. Until the advent of the Internet, academic libraries had no competition and their patrons were a captive audience. Students and faculty either learned the protocols and organizational principles of the library, no matter how esoteric or complex, or did without. In today's environment simplicity, efficiency and transparency, combined with savvy marketing, have become critical factors in patrons' decisions in selecting information resources. Ease of 
access is often considered more important than quality. Thus users eschew authoritative print reference sources for Internet ones of lower quality. The new market also means that competition is not a one-time phenomenon, but rather a present and future reality. Librarians must now confront disruptive innovation as a matter of routine.

As Jerry Campbell points out, the scholarly monograph remains the anchor of the academic library: Looking at current evidence, one may conclude that the print scholarly monograph is secure for the foreseeable future-the number of titles and editions grew substantially from 2002 through 2004 and the trend is expected to continue ${ }^{9}$, while e-books have failed to acquire more than a toehold in the market ${ }^{10}$. Nevertheless, the print scholarly monograph hinges on an unsustainable financial model ${ }^{11}$; a growing number of libraries are purchasing electronic monographs; and many scholarly works are consulted more often than read cover to cover, including reference works, many science books and textbooks ${ }^{12}$. Although current technologies, such as PDF and e-book readers, have failed to supplant the print codex, interest in the future of the e-book remains high on the part of business, funding agencies, technologists, and the public at large ${ }^{13}$. Furthermore, dissertations which are a source of many scholarly monographs are available online in increasing numbers. Considering the wide spectrum of disruptive change that electronic scholarly monographs would force upon the library, it may be wiser to assume that it will change, rather than bet on its immutability.

Thus, the shift to a digital environment brings the very identity of the librarian under question. Librarianship was built upon an ethos of service, but service can no longer be delivered effectively without the application of technology: Libraries must create a more compelling Web presence that attracts users. A combination of computing expertise has to be harnessed in the interests of delivering effective service that will provide a competitive advantage. In fact, a misplaced service ethos tethers librarians to services no longer desired by the majority of library users. The decline in reference questions is a telling sign that library efforts are misdirected ${ }^{14}$. The nature of the questions being asked indicates that they are driven more by structural barriers that libraries themselves impose between the patron and information, e.g., poorly designed and inconsistent computer interfaces, confusing buildings, and professional jargon-many of which were meant to add value to the information in the library. Moreover, information literacy classes are attended only when mandatory and open workshops are ignored ${ }^{15}$. Thousands of students successfully complete their degrees without the benefit of a single information literacy session. The value added by extensive cataloging records is also questionable. Librarians esteem a thorough catalog entry, but patrons are more often confused than informed by library conventions ${ }^{16}$. At the same time, the Web portal is maintained by overstretched systems units, even though it is the principal resource for the majority of academic patrons ${ }^{17}$.

Although competing for the same patrons, there are significant differences between the commercial players and the library. The profit motive is an obvious difference, after all librarians' paychecks are not tied to the information marketplace. Success will not yield raises, though abject failure may conceivably result in job losses. Perhaps less obvious, but arguably more important, is that in the commercial sphere the market players know that any misstep can yield rapid changes in the business venture. Altavista lost its preeminence very rapidly once Google arrived on the market, and there is little to prevent Google's sudden demise if any of its competitors were to peddle a better search algorithm ${ }^{18}$. There is also a difference in the scale of resources. For instance, in 2005, total book sales are estimated at $\$ 25$ billion $^{19}$, and academic publishers were responsible for about 12 percent of total sales ( $\$ 3$ billion). By comparison, Google's estimated revenue for 2006 is $\$ 9.6$ billion.

As stated above, the shift from'a predominantly analog information environment to a predominantly digital environment has a direct effect on library services. In a digital environment, the obstacles, or friction ${ }^{20}$, to the transmission of information are significantly lower than in an analog environment. This observation has two implications to library services: services that lowered friction in an analog environment do not necessarily have the same effect in a digital environment; and 'the Internet, by definition, is a distributed and universally accessible medium; and therefore efforts to centralize information miss the point ${ }^{21}$. For example, the intervention' of the reference librarian lowered friction 'on the path to accessing complex print indexes, but they now increase friction on the path to accessing digital databases. A better solution in the digital world would be designing effective, standardized interfaces. In a similar vein, library collections came into existence because they offered patrons a relatively convenient, cost effective, and necessarily centralized access to information. In the emerging digital environment, the costs of information (both in financial terms and in terms of obstacles to access) are decreasing and its availability is only a "click away."

The shift to a new information environment will require hard decisions from library administrators ${ }^{22}$. Considerable reallocation of human resources is in order. Like medieval scriptoria after Guttenberg, entire services should disappear in the face of obsolescence. Libraries should also consider opening its professional ranks to nonlibrarians, unless library schools rapidly revamp the curriculum to reflect the new competitive environment ${ }^{23}$. High-level skills in marketing, systems, and a new competitive attitude, so uncharacteristic of the traditional librarian, are now needed. The library profession needs a more compelling raison d'etre than overseeing glorified study halls or computer labs as a vision of its future. Library buildings, into which so many universities have invested untold millions, stand vulnerable to repurposing once its last anchor - the print academic monograph - is digitized ${ }^{24}$.

The authors also recognize that there are factors in the analysis of the profession's underlying assumptions that dampen the urgency for change. Universities are known for their institutional inertia, and, at most institutions, administrators are distracted by more urgent needs than changes affecting libraries. The cultural value attributed to libraries gives pause to administrators with a propensity to impose changes, after all who wants to be known as the destroyer of a cultural icon $^{25}$ ? Moreover, copyright law provides a perverse lever for publishers to slow the adoption of new scholarly paradigms that challenge their preeminence in the marketplace. Publishers of both scholarly monographs and serials have a vested financial interest in making sure that they maximize their investments which is only natural in a capitalist market - and will resist changes, such as open access, for as long as those are perceived to damage their commercial prospects. Libraries play an important role in the accreditation piece where collection size, staffing, etc. provide concrete measures of performance. 
Accrediting bodies have reassured the library community by picking up the theme of information literacy; thus assuring this largely library based enterprise a future for at least the near term. Nevertheless, these factors may not be enough to sustain the status quo in an environment which can change with breathtaking speed.

\section{Analysis}

Three areas central to the traditional identity of academic libraries are most immediately affected by the transition from an analog to a digital environment: services, the collection, and the library as a place. It is on these fronts that the library's role and value were maximized in the analog environment, when the print journal and the bound monograph reigned supreme. The transition to a digital environment. fundamentally affects all three by virtue of the fact that in a digital environment the locus of value shifts elsewhere. A closer analysis of how this shift affects libraries is warranted for future decisions and has to be driven by a thorough and franc understanding of the significance and implications of this shift.

\section{"Three areas central to the traditional identity of academic libraries are most immediately affected by the transition from an analog to a digital environment: services, the collection and the library as a place."}

\section{SERVICES}

The catalog is perhaps the most heavily used and expensive service any library provides. It is costly both in terms of technology and in terms of human resources. Not surprisingly, libraries have devoted a great deal of time, energy; and money toward reducing the expense of creating and maintaining the catalog. Already in the late nineteenth century, librarians were imagining ways to dilute cataloging costs by sharing cataloging records $^{26}$. These schemes remained impractical until the establishment of the first bibliographic utility in 1971 and the widespread adoption of automated library systems in the 1980s. Although shelf-ready plans permit considerable cost savings by outsourcing and streamlining much of the work, there remains much dissatisfaction with the catalog ${ }^{27}$.

The successful transition from card catalogs to online catalogs obscures the very conservative nature of the cataloging rules and the MARC record that are the foundations of the library catalog. Cataloging practices developed in the nineteenth century were carried over into the OPAC largely. unchanged. As libraries automated, records in catalog drawers became MARC records with more emphasis on display than searching or data normalization ${ }^{28}$. Books continued to be treated as revered physical objects and so were identified not only by title but by size, pagination, and publisher. The emphasis on inventory control resulted in precise known item searching, but they worked against users who approached the $O P A C$ as a resource discovery tool ${ }^{29}$. For the first generation of OPAC users, familiar with library card catalogs and no experience searching computer databases, the OPAC seemed a powerful tool.
Yet for a variety of reasons, the OPAC has failed to evolve, and for today's users, weaned on Yahoo and Google, the OPAC seems oddly out of place. It is difficult to search, its conventions are arcane and its technology dated. They have a Web veneer, but in contrast with current Web search tools, they retain the underlying structures of the original 1970s product. Basic features such as spell checking, context sensitive help and search suggestions, long desired, remain largely absent ${ }^{30}$.

\section{"...for a variety of reasons the OPAC has failed to evolve, and for today's users, weaned on Yahoo and Google, the OPAC seems oddly out of place."}

Ultimately, the OPAC works reasonably well as an inventory tool. It is far more precise than Google for many types of known item searches. However, if we expect it to work as a resource discovery.tool, then it fails. Its contents are limited in general to the holdings of the institution. For undergraduate students, this may be enough, but graduate students and faculty need access to more resources than most institutions can afford to purchase. Furthermore, all patrons now have access to databases that are far richer. Some, like WorldCat, suffer from many of the problems associated with the OPAC, but others such as Amazon and Google offer a rich discovery environment. As with most Internet search services, they are geared toward discovery because their business depends upon it:

To date, attempts to enrich the catalog have been limited to book covers, tables of contents and occasional attempts to catalog ephemera, articles, and other nontraditional materials. Such information is useful but fails to improve the underlying nature of research where each discovery opens paths to new materials. This is the basic concept behind Google and ISI's Science Citation Index, which use the relationships between information objects : to enhance discovery. Following this model, an enriched OPAC would include bibliographies that would link outward to additional resources, such as scholarly reviews, but also be mined to create more effective rankings. Although social bookmarking is a method being investigated ${ }^{31}$, unless it becomes a standard research method, it risks becoming a volunteer effort-that will wither from neglect.

Considering current limitations in the OPAC, it should be a surprise that libraries continue to promote their catalogs as discovery tools. To get a glimpse of a richer future, we should consider Google Scholar: For all its faults and limitations, it does something that no library system can match. It allows us to seamlessly search a wide variety of information from PubMed and Open Worldcat to Science Direct and Blackwell and links to the underlying articles. A user with the right $\mathbb{P}$ address can retrieve commercial and open access scholarly information and yet remain blissfully unaware of the Library's role in licensing them. Libraries can upload their holdings and OpenURL server addresses to Google to enhance access but increasingly this will be irrelevant as more publishers open their sites to Google's indexing agents. It also provides book records from WorldCat, which in turn, finds the nearest library that owns it. Google Scholar provides an eye-opening example of the issues raised by the obsolescence of the OPAC and traditional indexing 
services. And in contrast with the OPAC, Google and its competitors provide ample evidence that they understand the dire consequences of not developing their products. Chances are we have only seen the tip of its potential. To a great extent, the OPAC, in its current manifestation, can continue to exist for as long as the scholarly monograph remains its analog format. The eventuality of the scholarly monograph crossing the digital frontier implies a high risk that the library catalog will become irrelevant.

Another critical library service shaken by the transition to a digital environment is reference. In the 1990s when the effects of the Internet were first being experienced, there was a widely held view that reference services would be outsourced or managed through cooperative networks so that users might have $24 / 7$ assistance ${ }^{32}$. Instead something unexpected happened, reference services dropped precipitously ${ }^{33}$. This decrease was caused in part by a demographic dip, yet as the current undergraduate population rebounds, the use of reference services has not recovered to 1990 levels. There appear to be several reasons for these changes. Anecdotal evidence suggests that the term paper is assigned less often, replaced by exams and group projects requiring less research ${ }^{34}$. When students are required to perform research, they are able to bypass the library as the Web now offers many competing sources of information. While much maligned, Wikipedia affords easy access to useful information; its bibliographies and external links can lead users to authoritative sources of information. Although not as easy to search as Internet search engines, the wide availability of full text and bibliographic databases has made research easier to perform. Electronic journals are easier to use than their print and microfilm counterparts, and the universe of open access content is growing at a rapid clip. Library Web sites have lowered the barriers for access to information, decreasing the need for reference services.

Librarians have attempted to redress this trend by offering email and chat reference services, but even the successful programs do not begin to make up for the accumulated decrease in traffic at reference desks $s^{35}$. Increased efficiencies, an improving Web presence, and the increasing reliance on Web forms have also made patrons more self-sufficient. As collections and services go online and libraries' Web presence continues to adapt to the new medium, traditional service points should fade into oblivion.

To counter the decrease in demand, alternative roles had to be found to justify existing staffing levels at public services. One such alternative is the information literacy movement. But if reference requests are falling, and research is becoming easier to perform, why should there be an increased need for instruction? To date, libraries have been remarkably successful at selling this initiative and, as it is now enshrined in accreditation standards, its future for the short-term seems guaranteed, despite the fact that continual refinement of the library's Web presence should obviate the need for this service.

In each case, these services are becoming vestiges of an analog environment, propped up by pillars made of clay. While cataloging and reference indeed provided tangible and much valued services, in the digital environment they are a source of friction, supported by anachronistic practices, rationales anchored in an analog paradigm, and face obsolescence.

\section{Collections}

In the analog environment, the mission of the library was to collect monographs, serials, and other information artifacts. The larger the collection, the better the chances of it meeting the fleeting needs of patrons. In the case of serials, the caliber of the collection was not only determined by the number of titles but also by the length of the runs. Libraries assumed that much of the material they purchased had lasting value and would be either unavailable or more costly in the future. This notion was strengthened by anecdotal accounts of seemingly worthless collections used for unintended purposes, such as Holocaust survivors and their families using the New York Public Library's European telephone directory collection to track relatives and survivors ${ }^{36}$. In effect, librarians were building long tails of information and the length of the tail became the distinguishing feature of libraries; the pride of librarians.

Although no library has ever enjoyed infinite acquisitions budgets, the size of many budgets, especially in the 1970s, was large enough to make it a real challenge to spend them within the boundaries of a fiscal year. Blanket orders and subject profiles were created to outsource cumbersome selection processes, which hindered the speedy expenditure of allocated resources, notwithstanding their wasteful nature. The "Great Libraries" of the nation had the largest collections and longest tails, small libraries had but shadow collections, and their patrons were left wanting.

The shift from analog to digital information alters many of these factors, granted, the scholarly monograph's predominant format remains the print codex and a substantive number of serials have yet to make the switch to the digital medium. But enough has already changed for us to garner a good sense of the implications of digital collections: Government Documents and a large number of serials have already made the switch and a substantive number of new resources have been born digital. Foremost among the implications of this shift is the fact that most patrons favor digital formats over print for many of their information needs ${ }^{37}$. For patrons, the main concern is access to the information, which they want now. Fleeting needs result in a disregard to the long debate engaged by librarians over access versus ownership: to the patron there is no such dichotomy.

Digital collections are insensitive to geographic boundaries. Location, organization, and management are irrelevant in the new medium. Libraries no longer need to balance the efficiencies of a central, all encompassing collection with the convenience of departmental libraries. All patrons now enjoy the same level of access to the collection that was once reserved for the few. Similarly, government documents collections and the federal depository system make less and less sense in an ' environment in which a centralized electronic collection can serve dispersed networked users more effectively. Thus the library' traditional mission of warehousing collections, around which so many of the library's services and operations revolve, is challenged as the physical collection is subsumed by the digital one.

"...the library' traditional mission of
warehousing collections, around which so many
of the library's services and operations revolve,
is challenged as the physical collection is
subsumed by the digital one."


Since digital collections are seldom bought, but rather rented, the concept of building collections becomes anachronistic. A digital library assembles a series of rental contracts that meet current patron needs, renewed or cancelled according to negotiable terms. The majority of these contracts provide access to collections, rather than individual titles. Consequently, collections can be assembled and cancelled with little effort, in no time, and without physical constraints. As a result, today even small libraries can provide access to collections so vast that the number of titles no longer distinguishes the great from the lesser libraries ${ }^{38}$. In a digital environment, the distinguishing characteristic of great libraries is that they will create virtual environments that are compelling and efficient to use, and are sensitive to the patron's productivity.

These same forces are also being felt in the scholarly publishing world and their resolution will have a profound impact upon academic libraries ${ }^{39}$. Twenty years ago, futurist Harlan Cleveland wrote an article on what he called the information society ${ }^{40}$. In it he argued that as the cost of reproducing information dropped, information producers would find that sharing information was more profitable than selling it. There are many examples of this currently on the Web, but perhaps nowhere does his logic make more sense than in the realm of scholarly information and open access publishing. If the open access model's current momentum carries, and it succeeds, its impact upon libraries will be profound. It may solve the decades old serial inflation crisis, and it will make scholarly communications significantly more efficient, but it will make library journal collections a thing of the past. The patron then will have unhindered and free access to scholarly content, leaving the library out of the scholarly communications food chain.

\section{LIBRARY as SPaCE}

The importance attributed to the "library as a place" is often recited as an incantation whenever the impact of digital collections on libraries is discussed. Its truth is accepted as self-evident and its power to preserve the status quo left unchallenged. There is little doubt that the library has a cultural significance that resonates in our society. Yet the arguments supporting the importance of the library as place ignore the primary function of any library building to house and provide access to its collections. In traditional library buildings, most of the space is dedicated to storage while public spaces, such as reading rooms, occupy only a small percentage of a library's square footage. Although for years academic libraries have sprinkled study carrels and computer workstations among their collections, the physical requirements of housing thousands, or millions, of books have often resulted in large drab utilitarian spaces. The question of how to repurpose these spaces as the collections migrate to a predominantly digital format looms large for those institutions unable or unwilling to construct new facilities. The process of repurposing this space will force academic libraries to confront the veracity of the arguments concerning the intrinsic value of the place. Library directors would be well advised to start articulating rigorous arguments as soon as possible.

Libraries have not yet reached the stage at which their space is irrelevant, as they continue to support large circulating collections, and evidence suggests that this will continue for as long as the preferred format of the academic monograph is the codex. But print journals, reference, media, and government documents collections are already shrinking in size and may cease to exist altogether. Some science libraries, with predominately serial based collections, are likely to close entirely. While monographic collections are more stable, many libraries are aggressively weeding their collections or sending them to storage $^{41}$. The effects of this change can be seen in new library construction where the percentage of space devoted to warehousing materials is decreasing while study areas and public spaces increase.

In the absence of compelling arguments for new roles for library buildings, other entities are bound to step into the vacuum. Some shrewd administrators seem to be taking the initiative by proposing that the library become a center of student services ${ }^{42}$. Accordingly the library becomes the "one-stop-shop" from provider of information and study space all the way to being the technology support center, the writing center, and even the advising center. Others have brought in services traditionally found in student centers: cafes, dining facilities, meeting rooms, retail, and information spaces. Study spaces are increasing in size and are becoming less. Spartan. While these multipurpose facilities can reverse the drop in user visits, most of the services are not provided by librarians nor are their operations managed by the library's administration. Libraries may become landlords for providers of more compelling services.

In an environment where library services are replaced by study rooms, computer labs, and eateries, the argument supporting the view of the library as a place rings hollow. When users are drawn to the library primarily for these types of activities, the library will have to compete with the student center as place, the technology center as place, and the food court as place. If the profession fails to maintain a unique identity, then the library will become a legacy asset with depreciating value.

\section{Conclusions}

In postulating the technology $S$ curves as an explanation for the behavior of commercial enterprises, Richard N. Foster also observes that many if not most companies' success and peak performance is temporary ${ }^{43}$. Advances in technology yield discontinuous progression and inevitable turmoil among individual companies, as their fate shifts from success in exploiting a new technology to stasis, and then loss as new, and better, technologies are exploited by the competition. His analysis points out that established companies do not retain the advantage in the competitive marketplace, precisely because a sense of comfort and complacency tends to set in once a given technology starts yielding fortunes - which become blinders as emerging companies that exploit newer technologies are underestimated as viable competitors until it is too late. Might the fact that so many of the points made in this article were originally. articulated in the literature years ago, without changes in the practice of the profession, not be evidence of complacency? What catalyst will be necessary for the profession to realize that a new paradigm means radical changes?

Telling evidence that libraries are facing a technology $\mathrm{S}$ curve can be found in OCLC's Perceptions of Libraries and. Information Resources ${ }^{44}$. When asked which sources of information they used, the study found that 73 percent of college students used the physical library but only 47 percent used the online library compared to 75 percent for Internet search engines ${ }^{45}$. Furthermore, 89 percent begin their search with a search engine while only 2 percent begin their research at a Library Web site ${ }^{46}$. When asked which sources they preferred, 
72 percent answered search engines, 14 percent the physical library, and 10 percent the online library ${ }^{47}$. Libraries remain an important source of information for college students but one that lags far behind Internet search engines. Furthermore, their clear preference for online information does not extend to online libraries. Clearly libraries are not keeping apace of user expectations in this area.

In recognition of the new competitive environment in which libraries now operate, many libraries are already experimenting with new service models, workflows, and building redesigns ${ }^{48}$. Among these, it is worth mentioning the plethora of digital information services being implemented in many libraries ${ }^{49}$; the wide-spread adoption of new acquisitions and processing models, such as shelf-ready books, that have yielded efficiencies in processing workflows, and the recent construction and repurposing of many libraries across the nation. But as Foster points out, once established entities recognize the competitive threat in which they operate, their reflex is to fine-tune the timeproven model - obsolete though it may be - rather than recognizing that the marketplace has made a discontinuous switch to an altogether new model. The question of whether these changes are sufficient to reposition the academic library on the new "S curve" of the digital information paradigm remains unanswered and the authors are unconvinced of many of the changes being brandished at this point ${ }^{50}$.

"...once established entities recognize the
competitive threat in which they operate, their
reflex is to fine-tune the time-proven model -
obsolete though it may be - rather than
recognizing that the marketplace has made a
discontinuous switch to an altogether new
model."

The questions and challenges raised in this article are particularly compelling because libraries lost the first round in the new competitive environment: libraries offer better content for the task at hand, yet patrons flock elsewhere. Monetary costs are obviously not the issue for patrons, after all Google and Lexis-Nexis are equally free from their point of view. Academic librarianship needs to fundamentally revise its practices to become competitive in a digital environment.

Acknowledgments: The authors wish to thank Paul Philbin, William Strait, John Abbott, Wilson Stahl, and Jane Love for their patient and insightful comments as the manuscript for this article evolved into its current form.

\section{Notes AND Refrerences}

1. Richard N. Foster, Innovation: The Attacker's Advantage, Summit Books, New York, 1986.

2. Eric D. Beinhocker, The Origin of Wealth, Harvard Business School Press, Boston, 2006, pp. 254-258.

3. John Schuler argues that the digital "...revolution results in a new dialectic between those who produce and distribute information and those who seek to use it." His argument is about Government Document repositories, but it is a most relevant argument. See "The
Political and Economic Future of Federal Repository Libraries" The Journal of Academic Librarianship 31, 4 (2005) 377-82.

4. Daniel J. Cohen \& Roy Rosenzweig, "Web of Lies? Historical Knowledge on the Internet," First Monday 10 (December 2005): 12.

5. An unpublished study by the authors of Web use on public access computers at the University of Vermont's Bailey/Howe Library found that the most heavily visited domain was the University at large, excluding the library, followed by Facebook, with the Library's domain in third place. This was true despite the fact that the library's Web site was the homepage for all browsers and loaded whenever a user logged on to a computer. In addition; the Burlington Free Press's Web site got slightly more use than Lexis/ Nexis both of which were outdistanced by the Onion.

6. Arthur T. Hamlin, "University Library in the United States," University of Pennsylvania Press, Philadephia, 1981. For a more recent view see Lowry, Charles B. "When's this Paradigm' Shift Ending?" portal: Libraries and the Academy 2, 3 (2002) vii-xii.

7. Floridi, Luciano. "A Look Into the Future of ICT" Information Society, Jan/Feb2007, Vol. 23 Issue 1, pp. 59-64.

8. Jerry Campbell, Changing a Cultural Icon: The Academic Library as a Virtual Destination, Educause 41 (January/February 2006): 1.

9. Bowker Annual, (Medford, Information-Today, Inc., NJ, 2006), p. 516.

10. There are also important legal and social issues, in addition to the technological hurdles, to the success of e-books. See Clifford Lynch "The Battle to Define the Future of the Book in the Digital World" First Monday, (June 2001) 6,6.

11. Jason Epstein "Books@Google”.in The New York Review of Books $53,16$.

12. In one instance, the textbooks are actually, free to students as the publisher generates their profits from advertising. Owuor, Elizabeth "Online College Texts are Free, but Not Free From Ads" in Christian Science Monitor (Oct 12 2006) http://www.csmonitor. com/2006/1012/p15s01-legn.html.

13. Clifford Lynch "Battle to Define the Future of the Book in the Digital World" First Monday (June'2001), 6, 6) and Jason Epstein "Future of Books" MIT Technology Review January (2005) (online http://www.technologyreview.com/read_article.aspx?id=14064\& ch=infotech).

14. ARL statistics report a 40 percent decline in the median number of reference questions reported by members between 1997 and 2003. See Steve Coffman and Linda. Arret "To Chat or Not to ChatTaking Another Look at Virtual Reference" Searcher: 12, 7 (July/ August 2004) 38-46.

15. One indication of why this is true maybe the discrepancy between librarians evaluation of their patrons 'search skills and patrons' own assessment. Nora Paul and Kathleen A. Hansen "Reclaiming News Libraries" Library Journal vol. 107, no. 6 (2002) pp. 44-46.

16. Holly Yu \& Margo Young, The Impact of Web Search Engines on Subject Searching in OPAC, Information Technology and Libraries December 23 (4) (2004): 164-180.

17. Charles Martell "The Ubiquitous 'User: A Reexamination of Carlson's Deserted Library" Portal: Libraries and the Academy, vol. 5 , no. 4 (200), pp. 441-453.

18. Wade Roush, Search Beyond Google, Technology Review (March 2004): http://www.technologyreview.com/read_article.aspx? $\mathrm{id}=13505$.

19. Bowker Annual (Medford, NH: Information Today, Inc, 2006). 522.

20. Floridi, Luciano. "A Look Into the Future of ICT" Information Society, Jan/Feb2007, Vol. 23 Issue 1, pp. 59-64.

21. Wendy Pradt Lougee, Diffuse Libraries: Emergent Roles for the Resarch Library in the Digital Age Council on Library and Information Resources Reports (August 2002) accessed at http:// www.clir.org/pubs/reports/pub108/pub108.pdf.

22. Brinkley Franklin \& Terry Plum, "Library Usage Patterns in the 
Electronic Information Environment," Informationresearch 9 (4) (July 2004).

23. Lawrence Heilprin advocated for such changes more than twenty years ago. See "The Library Community at a Technological and Philosophical Crossroads: Necessary and Sufficient Conditions for Survival" originally published in 1980 and republished in Journal of the American Society for Information Science 42, 8 (1991) 566-573. For a more recent clamor for change see Changing roles of Academic and Research Libraries as part of ACRL's Future of Academic Libraries and Higher Education in http://www.ala.org/ ala/acrl/acrlissues/futureofacademiclibrariesandhighereducation/ changingroles.htm).

24. Jerry Campbell, "Changing a Cultural Icon: The Academic Library as a Virtual Destination" Educause 41-(1) (January/February 2006).

25 . Though that alone should not be a reason for solace, as Campbell aptly warns, after all there is precedent to academic libraries being subjected to draconian cuts. See Jerry Campbell "Changing a Cultural Icon."

26. "Cataloging-In-Source" Encyclopedia of Library and Information Science, vol. 4, (Marcel Dekker, NY, 1970), pp. 224-231.

27. Roy Tennant, Demise of the Local Catlog Library Journal (7/15/ 2007).

28. Roy Tennant "MARC Must Die" Library Journal (10/15/2002) and "MARC Exit Strategies" in Library Journal (11/15/2002).

29. Karen Coyle \& Diane Hillman, Resource Description and Access (RDA). Cataloging Rules for the 20th Century D-Lib. Magazine (January/February 2007).

30. Kristin Antelman, Emily Lynema, \& Andrew K. Pace, Toward a Twenty-First Century Library Catalog Information Technology and Libraries (September 2006): 128-139 and University of Windsor "ILS Assessment: A Background Document" (June 1, 2007) (found at http://www.accessola2.com/olita/insideolita/ wordpress $/ ? \mathrm{p}=60$ ).

31. Melissa L. Rethlefsen "Tags Help Make Libraries Del.icio.us" Library Journal (September 2007) http://www.libraryjournal.com/ article/CA6476403.html and Xan Arch "Creating the Academic Library Folksonomy: Put Social Tagging to Work at : Your Institution" ACRL News (vol. 68, 2) February 2007 http://www. ala.org/ala/acrl/acrlpubs/crlnews/backissues 2007/february07/ libraryfolksonomy.cfm.

32. One of the first efforts at creating a cooperative virtual reference network was the Library of Congress's CDRS service see "Reference 24/7: Libraries Test Collaborative Digital Reference Service", Library of Congress Information Bulletin (October 2000) http://www.loc.gov/loc/lcib/0010/ref.html. In 2002, this became a joint venture with OCLC which markets the service under the name Question Point see http://www.questionpoint.org/ and Jeffrey T. Penka "The Technological Challenges of Digital Reference" D-Lib (vol. 9, 2) $2003 \mathrm{http} / /$ www.dlib.org/dlib/february03/penka/ 02penka.html. There have been a number of successful implementations of this service most notably among public libraries which still believe it will be a long-term success story, see Peter Webster "Interconnected and Innovative Libraries: Factors Tying Libraries More Closely Together" Library Trends (vol 54, 3) 2006 pp. 382-393.

33. ARL Statistics 2003-04 (Washington, DC: Association of College and Research Libraries, 2005) http://www.arl.org/bm doc/arlstat04.pdf and Sandra L. De Groote, Kirstin Hitchcock and Richard McGowan "Trends in Reference Usage Statistics in an Academic Health Sciences Library" Journal of the Medical Library Associa- tion $(95,1) 2007$ pp. $23-30$. According to the Digital Library Foundation study Dimensions and use of the scholarly information environment"(2002) http://www.diglib.org/pubs/scholinfo/ only 0.6 percent of respondents wanted their institution to provide $24 / 7$ electronic reference service (question 16).

34. This is based upon the author's experience providing reference service over an 18 year period as well as conversations with faculty members.

35. Steve Coffman and Linda Arret "To Chat or Not to Chat -Taking Another Look at Virtual Reference" Searcher. 12, 7 (July/August 2004) 38-46 and Sandra L. De Groote, Kirstin Hitchcock and Richard McGowan "Trends in Reference Usage Statistics in an Academic Health Sciences Library". Journal of the Medical Library. Association $(95,1) 2007$ pp. 23-30.

36. "Pre War Directories" Lodz ShtetLinks url http://www.shtetlinks. jewishgen.org/lodz/phonedir.htm. Cymbler, Jeff: "Nineteenth- and Twentieth-Century Polish Directories as Resources for Genealogical Information." Avotaynu, Spring 1997 and more generally "Bezeq's new Web site Stymies Genealogical Searches" Jerusalem Post (April 25; 2007).

37. Carol Tenopir Use and Users of Electronic Library Resources: An Overview and Analysis of Recent Research Studies" (Washington, DC: Council on Library and Information Resources, 2003) http://. www.clir.org/pubs/reports/pub120/pub120.pdf surveys a large number of studies and concludes that undergraduate and graduate students have a strong preference for online resources.

38. Small colleges, members of large consortia, such as OhioLINK, may have-access to larger collections than many ARL libraries.

39. Laura Brown et' al., Ithaka Report "University Publishing in a Digital Age".

40. Harland Cleveland, "Information as "Resource" The Futurist (December 1982): 34-39.

41. Paul Gherman, "The North Atlantic Storage Trust: Maximizing Space, Preserving Collections" Portal 7 (3) (2007).

42. Miriam A. Drake, "Libraries are Alive and Thriving" Searcher 15 (1) (January 2007): It is worth noting that in this interview about the future of libraries and their roles, there is no mention of bibliographic instruction at all!.

43. Richard N. Foster, Innovation: The Attacker's Advantage (Summit Books, New York, 1986) Clayton Christiansen The Innovator's Dilemma is even more sanguine about the odds of legacy organizations remaining competitive over the long-term.

44. Perceptions of Libraries and Information Resources (2005) http:// www.oclc.org/reports/2005perceptions.htm.

45. Perceptions of Libraries and Information Resources (2005) http:// www.oclc.org/reports/2005perceptions.htm A-05.

46. Perceptions of Libraries and Information Resources (2005) http:// www.oclc.org/reports/2005perceptions.htm A-14.

47. Perceptions of Libraries and Information Resources (2005) http:// www.oclc.org/reports/2005perceptions.htm A-20.

48. Lynne Brindley, "Re-defining the Library" Library High Tech 24 (4) (2006)

49. Donatella Castelli, "Digital Libraries of the Future - and the Role of Libraries" :Library High Tech 24 (4) (2006).

50. In this competitive environment, libraries are challenged to provide patrons with something better than what other players, like Google, make available in the information marketplace. This challenge is unprecedented in the history of librarianship. See John MacColl "Google Challenges for Academic Libraries" Ariadne 46 (January 2006). 


\section{COPYRIGHT INFORMATION}

TITLE: The Library is Dead, Long Live the Library! The Practice of Academic Librarianship and the Digital Revolution

SOURCE: J Acad Libr 34 no2 Mr 2008

The magazine publisher is the copyright holder of this article and it is reproduced with permission. Further reproduction of this article in violation of the copyright is prohibited. To contact the publisher: http://www.elsevier.com/ 